\title{
Über die Volumenbestimmung der roten Blutkörperchen durch Zentrifugieren im Hämatokriten.
}

\author{
Von
}

Dr. med. Hans Koeppe.

Die Methoden zur Bestimmung des Volumens der roten Blutkörperchen kann man einteilen in indirekte und direkte. Bei den indirekten Methoden wird z. B. das spezifische Gewicht von Blut, Serum und den roten Blutkörperchen bestimmt und aus den drei Zahlen der Prozentgehalt des Blutes an Serum berechnet nach einer Formel (Grawitz), oder es wird der N-Gehalt nach Kjeldahl bestimmt von verschieden mit $0,6 \%$ iger $\mathrm{NaCl}$-Lösung verdünnten Sera und aus diesen Zahlen nach einer Formel das Volumen des Serums berechnet (Bleibtreu). Abgesehen davon, dass z. B. das Bleibtreu'sche Verfahren durch die Verwendung der $0,6 \%$ igen $\mathrm{NaCl}$-Lösung falsche Resultate liefert, würde es auch bei Verwendung von Lösungen gleichen osmotischen Drucks, wie ihı das Blut hat, doch recht umständlich, wie alle indirekten Bestimmungen, sein.

Erheblich einfacher, darum aber anscheinend ungenauer sind die direkten Volumenbestimmungen, bei denen von einem bestimmten Blutquantum die Blutkörperchen quasi in einem Hohlmass, wie Erbsen oder dergleichen, gemessen werden.

Diese Verfahren sind: Erstens das Hämatokritverfahren, nach Hedin und Gärtner: Blut wird gemessen, mit einer Kaliumbichromatlösung gemischt, zentrifugiert, das Blutkörperchensediment gemessen und daraus die Volumenprozente der Blutscheiben bestimmt. Das Verfabren leidet daran, dass die Mischflüssigkeit das Volumen der roten Blutscheiben ändert; demnach gibt dieses Verfahren wohl das Volumen der roten Blutscheiben in der $2^{1 / 2} \%$ igen Kaliumbichromatlösung an, das Volumen der roten Blutkörperchen im Plasma aber nur dann, wenn das Plasma zufällig denselben osmotischen Druck hat wie die $2^{1 / 2} \%$ ige Kaliumbichromatlösung, was manchmal zutrifft, oft aber nicht. 
Die Sedimentierunosmethode von Bi ernacki, nach welcher einige Kubikzentimeter Blut mit oxalsaurem Natron in Pulverform versetzt werden, wodurch die Gerinnung verhindert wird, muss, abgesehen von den Mängeln der Methode, die in der verschiedenen Sedimentierung verschiedener Blutproben liegen, falsche - und zwar zu kleine -- Resultate ergeben, da das Volumen der sedimentierten Blutkörperchen infolge des Salzzusatzes dem Volumen der Blutscheiben in einer Lösung von höherem osmotischem Druck entspricht, als das Plasma ihn hat.

Jeder Zusatz zum Blute, sei es in Form einer Lösung, sei es als ein Salz, verändert den osmotischen Druck des Plasmas und damit das Volumen der Körperchen; eine direkte Messung ist dann nicht mehr möglich.

Die einzige Methode, obne Zusatz das Volumen der roten Blutkörperchen direkt zu messen, ist die Methode: Zentrifugieren von Blut in graduierten Ölpipetten (Hämatokrit nach Koeppe).

Die Einwände, welche dieser wie allen andern Metboden gemacht werden, sind: 1 . Zwischen den sedimentierten Blutkörperchen befindet sich noch etwas PJasma; es ist das an den Pipetten abgelesene Volumen nicht das wirkliche, sondern ein etwas zu grosses. 2. Je nach dem Grade der Sedinentation ist das in den Lücken zwischen den roten Blutscheiben befindliche Quantum Plasma verschieden gross, und zwar hängt die Sedimentation wieder ganz von der Grösse der Zentrifugalkraft $a b$, welche einwirkte. Diese Kraft wird bei verschiedenen Zentrifugen verschieden, auch bei derselben Zentrifuge nicht immer die gleiche sein. Diese vollkommen berechtigten Einwände gegen das Verfahren, welches, wie gesagt, absolut genaue Zahlenwerte nicht bringen kann, haben gegen die Methode eine Abneigung hervorgerufen, so dass auch die relativen Werte nicht gewürdigt worden sind, wie sie es eigentlich verdienen.

Es ist ohne weiteres klar, dass dann vergleichbare Werte für das Volumen der roten Blutkörperchen mit der Zentrifuge zu erhalten sind, wenn bei all en Untersuchungen die gleiche Zentrifugalkraft zur Anwendung kommt; praktisch vorteilhaft ist dabei, dass die Zentrifugalkraft möglichst gross sei. Es war demnach eine Zentrifuge zu konstruieren mit möglichst hoher Tourenzahl und einer Vorrichtung, durch welche konstant die Tourenzahl direkt abgelesen werden konnte. Versuche mit gleicher Tourenzahl bei gleichem Radius der Zentrifuge und gleichlangem Zentrifugieren werden dann miteinander einwandsfrei vergleichbar. 
Den unablässigen Bemühungen meines Freundes Geh. Sanitätsrats Dr. Thile ni us-Soden (Taunus) ist es nun gelungen, nach vielen Versuchen und grossen Geldopfern, eine Zentrifuge zu bauen, welche diese Anforderungen in geradezu idealer Weise erfüllt. Die Mitteilungen hierüber werden durch ihn selbst erfolgen.

Wird in einer solchen hocbtourigen Zentrifuge Blut ohne Zusatz in gutgereinigten Pipetten zentrifugiert, so gelingt es Blutkörperchen und Blutplasma vor der Gerinnung zu trennen. Die roten Blutkörperchen bilden eine Bodenschicht mit scharfer Begrenzung gegen das vollkommen klare, weisse Plasma. Dabei zeigt sich aber bei einer Umdrehungsgeschwindigkeit von über 5000 Touren in der Minute, dass die Blutkörperchensäule lackfarben ist.

Als ich diese Beobachtung zum ersten Male machte, war mir ihre Bedeutung nicht sofort klar; anfangs habe ich auch die Lackfärbung auf eventuelle Verunreinigungen der Pipetten bezogen; doch als ich zu einer Vorstellung von der chemischen Natur der Hülle der roten Blutkörperchen gekommen war, nämlich, dass die roten Blutscheiben von einer fettartigen Wand ungeben seien, fand ich die Erklärung für das Phänomen:

Wenn die Blutscheiben von einer fettähnlichen Hülle umgeben sind, welche infolge ihres Fettcharakters transparent, durchscheinend ist, so wird, wenn Fetthülle an Fetthülle liegt, die ganze Masse durchscheinend sein, eben lackfarben. Wie eine Emulsion undurchsichtig, deckfarben ist, so ist auch Blut undurchsichtig, deckfarben; haben sich von einer Emulsion die Tröpfehen zu Boden gesenkt, und befindet sich keine Flüssigkeit mehr zwischen denselben, so erscheint das Sediment klar durchscheinend, eben lackfarben; gerade so müssen die roten Blutscheiben klar durchsichtig, lackfarben erscheinen, wenn sie sich so dicht berühren, dass keine Flüssigkeit mehr zwischen ihnen ist, keine verschiedene Brechung der Lichtstrahlen stattfindet.

Die Lackfarbe der Blutkörperchensäule ist also ein Beweis dafür, dass sich kein Plasma mehr zwischen den einzelnen Körperchen befindet; die hohe Zentrifugalkraft drängt die roten Blutscheiben so dicht aneinander, dass alle Flüssigkeit zwischen ihnen verschwindet. Wenn aber nichts mehr zwischen den einzelnen Körperchen ist, so gibt die Blutkörperchenseheibe auch das wahre, das absolute Volumen der Blutscheiben im Blute an; die Lackfärbung ist der Beweis hierfür. Die Thilenius'sche Zentrifuge gestattet demnach 
nicht allein eine Volumenhestimmung der roten Blutsclieiben bei stets bekannter und regulierbarer Zentrifugalkraft, sondern sie ermöglicht bei entsprechender Tourenzahl die Bestimmung des absoluten Volumens der roten Blutkörperchen.

Das frisch aus einer kleinen Fingerwunde quellende Blut wird o hne jeden Zusatz in den graduierten Pipetten zentrifrugiert; das abgelesene Volumen muss demnach das Volumen der Körperchen im Plasma sein. Da zwischen den roten Blutscheiben keine Lücken mehr sind, wird eben das abgelesene Volumen das absolute Volumen der roten Blutscheiben in Prozenten des Volumens vom Gesamtblut darstellen. Zeigt $z$. B. der Hämatokrit 44 Vol.-Proz. roter Blutscheiben an, so heisst das: in $100 \mathrm{ccm}$ Blut nehmen die roten Blutscheiben $44 \mathrm{ccm}$ ein. Wird gleichzeitig von demselben Blut die $\mathrm{Zahl}$ der roten Blutscheiben im Kubikmillimeter bestimmit, so lässt sich das Volumen eines roten Blutkörperchens berechnen, und zwar, wie gesagt, das absolute Volumen.

Das absolute Volumen der roten Blutscheiben durch Zentrifugieren zu bestimmen, ist möglich, weil die roten Blutkörperchen elastisch sind, ihre Form so ändern können, dass sie sich aneinanderschmiegen, alle Flüssigkeit zwischen sich wegdrängen können. Wären die Blutscheiben starre Gebilde, so liesse sich natürlich auf diesem Wege keine Volumenmessung ausführen. So aber ist es möglich, denn das Volumen ändert sich nicht, wenn auch die Form sich ändert.

F. Weidenreich ${ }^{1}$ ) sieht allerdings in einer Formänderung der roten Blutkörperchen auch eine Volumenänderung: so ist nach ihm der Übergang der roten Blutscheiben aus der Glockenform in die Scheibchenform mit einer Volumenänderung verbunden (S. 21): „Wir wissen aber, dass im gelassenen Blute die Körperchen auch im eigenen Plasma sehr rasch Scheibenform annehmen, also ihr Volumen verringern." Auch nach den Vorstellungen F. Weidenreich's ${ }^{2}$ ) ist das aber durchaus nicht nötig. Das von ihm selbst an anderer Stelle gebrauchte Bild, der Vergleich eines roten Blutkörperchens mit einem nur teilweise gefüllten Gummiball, zeigt das sehr deutlich. Weidenreich ${ }^{2}$ ) sagt (S. 43): „Machen wir diesen

1) F. Weidenreich, Ergebnisse der Anatomie u. Entwicklungsgeschichte. Die roten Blutkörperchen I Bd. 13. 1903.

2) F. Weidenreich, Arch. f. mikrosk. Anat. u. Entwicklungsgesch. Bd. 61. 1902. Studien über das Blut. 
(den dünnwandigen Gummiball) völlig luftleer und füllen ihn zur Hälfte mit Wasser, so nimmt er die Form einer halbkugeligen Glocke an, genau wie die Blutkörperchen." Einen so präparierten Gummiball kann man nun sehr leicht in alle möglichen anderen Formen überführen, auch in eine Scheibchenform, ohne dass sein Volumen sich im geringsten ändert. In der Blutbahn sehen wir die vielen Blutscheiben die verschiedenartigsten Formen annehmen und schreiben dies Vermögen eben der vollkommenen Elastizität der Scheibchen zu, ohne nur im geringsten dabei an eine Volumenänderung zu denken. Die Bedeutung, welche Weidenreich der Form der roten Blutscheiben bei der Volumenbestimmung beilegt, ergibt sich aus folgendem:

„Man hat ohne weiteres vorausgesetzt, dass das Volumen der Körperchen im eigenen Plasma keine Änderung erleide; unterstützt wurde diese Vorstellung durch die falsche Annahme, dass die Scheibenform die normale wäre. Den Volumenbestimmungen dürfte ein absoluter Wert also nur dann zukommen, wenn diesen veränderten Verhältnissen Rechnung getragen wird; die Forscher, die bisher auf diesem Gebiete gearbeitet haben, hätten zunächst Methoden ausfindig zu machen, die gestatten, eine Volumenbestimmung mit vollständig unveränderten Glockenformen auszuführen, die aber natürlich nicht künstlich in hypisotonischen Salzlösungen erzeugt sein dürfen."

Ich babe schon hervorgehoben, dass bei der Volumen bestimmung der roten Blutkörperchen durch Zentrifugieren in graduierten Pipetten die Form derselben nebensächlich ist, auch nach den Vorstellungen F. Weidenreich's; gerade dass die Blutkörperchen in ihrer Form sich dem ihnen zur Verfügung gestellten Raum anpassen, ermöglicht überhaupt nur die Volumenmessung auf diese Art. Setzen wir einen Öltropfen auf die Fingerkuppe und stechen durch diesen in den Finger, so wird der herausquellende Blutstropfen von einer Ölschicht umgeben und so jede Verdunstung und dadurch eventuelle Konzentrationsänderung des Plasmas vermieden; unmittelbar in die Pipette einlaufen gelassen, sind jetzt in der Pipette die roten Blutkörperchen genau unter den gleichen Verhältnissen, wie sie F. Weidenreich zwischen zwei Deckgläschen beobachtete. Unter solchen Verbältnissen zentrifugiert, muss das gefundene Volumen der roten Blutscheiben tatsäehlich dem Volumen der Körperchen in der Blutbahn gleich sein, und als absolutes Volumen der roten 
Blutkörperchen ist es zu betrachen, wenn $z$ wischen den einzeluen Körperchen sich nichts anderes, kein Plasma befindet, was sich durch die Lackfarbe der Blutkörperchenscheibe dokumentiert. Ibre Form haben die roten Blutkörperchen durch das Zusammenpressen wohl verändert, aber nicht ihr Volumen.

Eine Volumenänderung durch osmotische Druckänderung ist eben ausgeschlossen, da in dieser Richtung keine Eingriffe stattgefunden haben.

Man könnte noch fragen, ob die mechanische Gewalt des Znsammenpressens nicht volumenändernd eingewirkt hat. Es wäre denkbar, dass aus den roten Blutkörperchen durch die Zentrifugalkraft Flüssigkeit abgepresst worden wäre. Dem stehen gewichtige Gründe entgegen: Alle Untersuchungen ergaben, dass die roten Blutkörperchen von einer sogenannten halbdurchlässigen Membran umgeben sind; eine solche Membran ist nur durcbgängig für Wasser. Von dem Inhalte der roten Blutscheiben könnte also nur Wasser (und in diesem auch die diffusiblen Stoffe) abgepresst werden. Um durch eine balbdurchlässige Wand reines Wasser abzupressen, ist ein hydrostatischer oder mechanischer Druck nötig, der grösser ist, als der osmotische Druck der Lösung beträgt, von welcher das Wasser abgepresst werden soll. Um aus den roten Blutscheiben Wasser abzupressen (ohne Verletzung der Wand!), wäre demnach ein Druck von mehr als sieben Atmosphären notwendig; der Druck kommt aber in der Zentrifuge nicht zur Wirkung.

Dieser Einwand wäre somit auch entkräftet. Das Problem der absoluten Volumenbestimmung der roten Blutkörperchen ist als gelöst anzusehen. 